\title{
Effects of atoms and molecules adsorption on electronic and magnetic properties of s-triazine with embedded Fe atom: DFT investigations
}

\author{
Yusuf Zuntu Abdullahi ${ }^{a, b, *}$, Tiem Leong Yoon ${ }^{\mathrm{a}}$, Mohd Mahadi Halimª ${ }^{\mathrm{a}}$ Md. \\ Roslan Hashim ${ }^{\mathrm{a}}$, Thong Leng Lim ${ }^{\mathrm{c}}$ \\ ${ }^{a}$ School of Physics, Universiti Sains Malaysia, 11800 Penang, Malaysia \\ ${ }^{b}$ Department of Physics, Faculty of Science, Kaduna State University, P.M.B. 2339 \\ Kaduna State, Nigeria \\ ${ }^{c}$ Faculty of Engineering and Technology, Multimedia University, Jalan Ayer Keroh \\ Lama, 75450 Melaka, Malaysia
}

\begin{abstract}
We employ first-principles calculations to study the mechanical, geometrical, electronic and magnetic properties of $\mathrm{Fe}$ atom embedded s-triazine $\left(\mathrm{Fe} @ \mathrm{C}_{6} \mathrm{~N}_{6}\right)$ system under the influence of external environment. Our results show that the binding energy of $\mathrm{Fe} @ \mathrm{C}_{6} \mathrm{~N}_{6}$ can be modulated by an applied tensile deformation and perpendicular electric field. The non-magnetic semiconducting property of pure s-triazine sheet $\left(\mathrm{C}_{6} \mathrm{~N}_{6}\right)$ is found to change upon embedding of $\mathrm{Fe}$ atom in the porous site of the sheet. It is revealed that the $\mathrm{Fe} @ \mathrm{C}_{6} \mathrm{~N}_{6}$ system exhibits half-metallic electronic character with a magnetic moment in the the order similar to that of an isolated Fe atom. Furthermore, electronic and magnetic properties of the Fe@ $\mathrm{C}_{6} \mathrm{~N}_{6}$ systems are preserved up to a maximum value of $10 \mathrm{~V} / \mathrm{nm}$ in electric field strength and $6 \%$ tensile strain. Interestingly, we find that the half-metallic electronic character of $\mathrm{Fe} @ \mathrm{C}_{6} \mathrm{~N}_{6}$ system can be tuned into a semiconductor via adsorption of atoms and molecules into the $\mathrm{Fe} @ \mathrm{C}_{6} \mathrm{~N}_{6}$ system. The magnetic moment of $\mathrm{Fe} @ \mathrm{C}_{6} \mathrm{~N}_{6}$ with adsorbed atoms/molecules is also modified. Our findings may serve as a guide for future applications of $\mathrm{Fe} @ \mathrm{C}_{6} \mathrm{~N}_{6}$ structures in spintronics devices.
\end{abstract}

Keywords:

\footnotetext{
* Corresponding author

Email addresses: yusufzuntu@gmail.com (Yusuf Zuntu Abdullahi), tlyoon@usm.my (Tiem Leong Yoon)
} 


\section{Introduction}

Currently there is an intense search for suitable substrates for transition metal (TM) atoms encapsulation [1],[2], [3]. The central concern in the encapsulation is to ensure that the substrate remains inert and strongly binds to the TM atoms. Moreover, the appropriate substrate is expected to preserve its intrinsic properties and that of bound TM atoms. Two-dimensional (2D) carbon-based and related surfaces with compacted hexagonal rings have been a frequent choice for trapping TM atoms [4], [5], [6], [7] due to their desirable surface properties. Numerous works have so far been done to investigate the stable geometries and electronic properties of TM atoms adsorption on graphene and boron nitride sheets [7], 8, ,9]. However, their reports have shown that the adatoms tight weekly on these $2 \mathrm{D}$ surfaces as a result of low adsorption energies. Additionally, the large surface free energy of the TM atoms would make them aggregate easily to form cluster on these surfaces. To ensure the immobility of the TM atoms on the surface, various defect sites have been proposed [8]. Creation of defect sites would presumably bind the TM atoms firmly to the surface. However, forming regular defect sites experimentally may not be possible due to influence of external environment. Thus, much efforts have been made to synthesis 2D materials with inherently defined porous sites [10].

Among the recently synthesized porous 2D materials [11], graphitic carbon nitride $(\mathrm{CN})$ sheet has received much attention [12], [13]. This is due to its potential as a right candidate for various applications [14, [15], [16], [17], [18]. Graphitic CN belongs to a group of allotrope with a common chemical formula $g-\mathrm{C}_{x} \mathrm{~N}_{y}$, where $x$ and $y$ represent the number of $\mathrm{C}$ and $\mathrm{N}$ atoms in the unit cell. For example, single triazine-based graphitic $\mathrm{CN}$ has a chemical formula g-s- $\mathrm{C}_{3} \mathrm{~N}_{4}$ whereas tri-single triazine-based (heptazine) graphitic $\mathrm{CN}$ is named g-t-s- $\mathrm{C}_{3} \mathrm{~N}_{4}$ [13]. The hexagonal rings in the unit cell of heptazine are compacted in an abreast manner. s-triazine with a chemical formula g- $\mathrm{C}_{6} \mathrm{~N}_{6}$ is another allotrope of graphitic $\mathrm{CN}$ in which two of its hexagonal rings (g$\mathrm{C}_{3} \mathrm{~N}_{3}$ ) are separated via a $\mathrm{C}-\mathrm{C}$ bond [12]. Depending on the composition of $\mathrm{C}$ and $\mathrm{N}$ in the hexagonal rings and unit cell, these allotropes can have different electronic properties ranging from semiconducting to half-metallic. For instance, triazine-based $\mathrm{g}-\mathrm{C}_{4} \mathrm{~N}_{3}$ is another allotrope of graphitic $\mathrm{CN}$ which possess a ferromagnetic ground state with half metallic electronic character 
[19] whereas the rest of the allotropes are non-magnetic with wide or small band gaps [12], [13].

To search for a suitable spintronic material such as diluted magnetic semiconductor, first-principles calculations of TM atoms embedded in semiconducting CN sheet have been performed [1], 2, ,3]. Choudhuri et al.. recently reported the findings of TM embedded g- $\mathrm{C}_{3} \mathrm{~N}_{3}$ (TM@g- $\mathrm{C}_{3} \mathrm{~N}_{3}$ ) systems based on density functional theory (DFT) [20]. The TM atoms (Cr, Mn and $\mathrm{Fe}$ ) embedded $\mathrm{g}_{-} \mathrm{C}_{3} \mathrm{~N}_{3}$ systems are found to be dynamical, thermally and mechanically stable. Their report also show that $\mathrm{Cr}, \mathrm{Mn}$ and $\mathrm{Fe}$ embedded in the g-t- $\mathrm{C}_{3} \mathrm{~N}_{3}$ systems exhibit high temperature ferromagnetism and high magnetic anisotropy energy (MAE) with a peak value per atom occurring in $\mathrm{Cr} @ g-t-\mathrm{C}_{3} \mathrm{~N}_{3}$.

TM embedded graphitic carbon nanostructures can also be used for heterogeneous catalysis, hydrogenation of $\mathrm{CO}_{2}$ and as membrane for separation of gases [21], 222, [23], 224],[25]. A recent theoretical study predicts excellent catalytic activities for single atomic catalyst (SAC) of TM embedded $\mathrm{C}_{2} \mathrm{~N}$ systems [24]. Additionally, an effective catalysis of hydrogenation of $\mathrm{CO}_{2}$ into methanol on the copper embedded graphene system has been demonstrated by Sirijaraensre and Limtrakul [25]. Although good catalytic behavior has been reported for the $\mathrm{SAC}$ of TM embedded $\mathrm{C}_{2} \mathrm{~N}$ systems, a comprehensive understanding of various types of atoms and molecules adsorbed onto their surfaces is still lacking. In this work, we investigate the structural, electronic and magnetic properties of $\mathrm{Fe}$ embedded s-triazine sheet with various adsorbed atoms and molecules. We begin by analyzing the Fe embedded s-triazine without the adsorbed atoms and molecules. Then, we introduce these atoms $(\mathrm{C}, \mathrm{N}, \mathrm{O}, \mathrm{H})$ and molecules $\left(\mathrm{CH}_{4}, \mathrm{~N}_{2}, \mathrm{O}_{2}, \mathrm{H}_{2}, \mathrm{CO}, \mathrm{CO}_{2}\right)$ at a distant height above the porous site at which the $\mathrm{Fe}$ is situated. The relaxed Fe embedded s-triazine with adsorbed atoms and molecules systems are then further analysed.

\section{Conputational method}

We use QUANTUM ESPRESSO package [26] to carry out spin-polarised DFT [27] calculations within Perdew-Burke-Enzerhof (PBE) approximation [28]. Ultrasoft pseudopotential method is employed to treat the core and valence electrons of $\mathrm{C}, \mathrm{N}$, and Fe (semi-core included) atoms [29]. A plain wave basis set with kinetic energy cut-off of $550 \mathrm{eV}$ was used to expand the wave functions. Marzari-Vanderbilt smearing method with Gaussian spreading 
is employed [30] to aid the convergences of our systems. The Brillouin zone (BZ) is sampled with $8 \times 8 \times 1$ and $15 \times 15 \times 1$ Mankhorst-Pack k-point meshes for the self-consistent field and density of state calculations respectively [31]. The planar sheet is treated with periodic boundary condition and a thick vacuum space of $16 \AA$ along the $z$-direction to avoid interaction between periodic layers. All geometries are fully relaxed using the BFGS quasi-Newton algorithm until Hellmann-Feynman force tolerance on each atom was smaller than $0.05 \mathrm{eV} / \AA$.

The optimized geometries of $2 \times 2$ pure s-triazine sheet $\left(\mathrm{C}_{6} \mathrm{~N}_{6}\right)$ and Fe embedded $\mathrm{C}_{6} \mathrm{~N}_{6}$ sheet $\left(\mathrm{Fe} @ \mathrm{C}_{6} \mathrm{~N}_{6}\right)$ are displayed in Fig. 1(a). All $\mathrm{N}$ atoms have $\mathrm{sp}^{3}$-like hybridized structure, whereas each $\mathrm{C}$ atom which is bonded to three atoms has $\mathrm{sp}^{2}$-like hybridized structure. The relaxed $\mathrm{C}-\mathrm{C}$ bond length $d$ linking the s-triazine units in $\mathrm{Fe} @ \mathrm{C}_{6} \mathrm{~N}_{6}$ system and $\mathrm{C}-\mathrm{N}$ bond lengths $l$ in the embedded Fe atom cavity are in the range of 1.47-1.50 $\AA$ and $1.35-1.37 \AA$ respectively. The calculated values agree well with the reported results [12]. The optimized lattice constant in the Fe@ $\mathrm{C}_{6} \mathrm{~N}_{6}$ is found to be $14.20 \AA$.

\section{Results and Discussions}

We used the expressions in Eq. (1) to compute the mechanical properties, such as in-plane stiffness $Y$ (Young modulus), and Poisson's ratio v:

$$
\begin{aligned}
Y & =m_{11}\left(1-v^{2}\right) \\
v & =\frac{m_{12}}{m_{11}}
\end{aligned}
$$

The variables $m_{11}, m_{12}$, (known as elastic constants) can be deduced from Eq. (2).

$$
\begin{aligned}
m_{11} & =\left.\frac{1}{A_{0}}\left(\frac{\partial^{2} E}{\partial s^{2}}\right)\right|_{s=0} \quad(\text { uni }- \text { axial }) \\
2\left(m_{11}+m_{12}\right) & =\left.\frac{1}{A_{0}}\left(\frac{\partial^{2} E}{\partial s^{2}}\right)\right|_{s=0} \quad(\text { bi }- \text { axial })
\end{aligned}
$$

where $A_{0}, E$, and s are equilibrium unit-cell area, strain energy and applied deformation. At each 0.005 applied deformation (within the harmonic region for both bi- and uni-axial tensile strains, see Fig. 2) in the $x y$-plane, the structure is fully relaxed. The calculated in-plane stiffness is $1193.2 \mathrm{GPa} \cdot \AA$ $(=119.32 \mathrm{~N} / \mathrm{m})$, lower than the in-plane stiffness of pure heptazine sheets 
[13. The Poisson's ratio 0.18 is in the same order as that of graphene sheet 32. The bulk modulus is determined from the product of equilibrium area and the second gradient of deformation energy with respect to area of the $\mathrm{Fe} @ \mathrm{C}_{6} \mathrm{~N}_{6}$ system, which is written as

$$
G=A \times\left.\left(\frac{\partial^{2} E}{\partial A^{2}}\right)\right|_{A_{m}}
$$

The variables in the Eq. (3) are defined as follows: $A, U$ and $A_{m}$ represent the area of the $\mathrm{Fe} @ \mathrm{C}_{6} \mathrm{~N}_{6}$ sheet, the bi-axial deformation energy and the equilibrium area of $\mathrm{Fe} @ \mathrm{C}_{6} \mathrm{~N}_{6}$ respectively. The calculated bulk modulus $86.49 \mathrm{~N} / \mathrm{m}$ is less than the value for Mn-CN1 system reported in [1]. The difference in the calculated elastic constants in comparisons with previously related structures can be related to the weakening in the bonding networks of the hexagonal rings in the structures. In Table 2 we show the values of binding energy $E_{b}$ and the structural parameters $h$ and $d$ obtained for different deformations in the range $\pm 2 \%$. By applying strain, the height $h$ (difference between the height of $\mathrm{Fe}$ and the average height of all atoms in the $\mathrm{C}_{6} \mathrm{~N}_{6}$ sheet) value of the $\mathrm{Fe}$ in the relaxed $\mathrm{Fe} @ \mathrm{C}_{6} \mathrm{~N}_{6}$ sheet do not change. Hence, approximately zero $h$ confirms the planar structure of the $\mathrm{Fe}_{0} \mathrm{C}_{6} \mathrm{~N}_{6}$ sheet. $E_{b}$ is determined from Eq. (4) which is given by:

$$
E_{b}=\left(E_{\mathrm{C}_{6} \mathrm{~N}_{6}}+E_{\mathrm{Fe}}\right)-E_{t}
$$

where $E_{t}, E_{\mathrm{C}_{6} \mathrm{~N}_{6}}$ and $E_{\mathrm{Fe}}$ denote the total energy of $\mathrm{Fe} @ \mathrm{C}_{6} \mathrm{~N}_{6}$ system, the energy of bare $\mathrm{C}_{6} \mathrm{~N}_{6}$ sheet, and the total energy of an isolated Fe atom. $E_{b}$ for unstrained Fe@ $\mathrm{C}_{6} \mathrm{~N}_{6}$ system is equal to $4.73 \mathrm{eV}$. Our computed $E_{b}$ value is consistent with the previous work [33]. It can also be seen that the Fe@ $\mathrm{C}_{6} \mathrm{~N}_{6}$ structure is more stable for positive binding energy and attained metastable state at a maximum $6 \%$ tensile strain. It is clearly shown in Table 2 that binding energy at a metastable state which is $6 \%$ tensile strain is found to be negative. The decrease in binding energy as a function of tensile strain can be explained as follows. Based on the definition of strain energy $E$ (i.e., product of square of strain and the elastic constants) under harmonic deformations, an increasing $E$ value stands for energetically favorable elastic moduli. Thus, for an increasing negative strain energy $E$ of the $\mathrm{Fe} @ \mathrm{C}_{6} \mathrm{~N}_{6}$ system (see Table 2), the binding energy according to Eq. (4) should correspondingly decrease. Table 2 illustrates the uniform increase in $d_{\mathrm{Fe}-\mathrm{N}}$ and $d$ bond lengths as a result of distortion in the $\mathrm{Fe} @ \mathrm{C}_{6} \mathrm{~N}_{6}$ structure caused by the tensile deformations. 
It is known that pure $\mathrm{C}_{6} \mathrm{~N}_{6}$ sheet is a non-magnetic semiconductor, thus the induced magnetism in the $\mathrm{Fe} @ \mathrm{C}_{6} \mathrm{~N}_{6}$ system is mainly from Fe atom (see $M_{\mathrm{Fe}}$ in Table 2). For unstrained Fe@ $\mathrm{C}_{6} \mathrm{~N}_{6}$ system, the estimated magnetic moment per unit cell is $3.74 \mu_{\mathrm{B}}$, which is consistent with the recent report 33. The magnetic moments are also evaluated for different applied tensile strains. It can be seen in Table 2 that the magnetic moment is less sensitive to the applied strain. This shows that the interaction between the Fe atom and the surrounding atoms in the porous site did not reduce the number of unpaired electrons in the d orbital of Fe atom. According to the results from Lowdin's charge analysis [34, the charge transfer $Q$ into $\mathrm{C}_{6} \mathrm{~N}_{6}$ sheet is contributed mainly by s, p orbitals of Fe atom. There is also a mixed bonding nature (ionic and covalent bonding) which is depicted in the charge-density difference plot (see Fig. 1(c)) by charge depletion between the atoms and localisation around the most elecronegative $\mathrm{N}$ atoms.

To analyze the modulation on the electronic properties of the Fe-embedded s-triazine system, we plotted the electronic band structure and corresponding total and projected density of states. As can be clearly seen in Fig. 3(i), pure $\mathrm{C}_{6} \mathrm{~N}_{6}$ is nonmagnetic semiconductor. If $\mathrm{Fe}$ atom is embedded in the porous site of the $\mathrm{C}_{6} \mathrm{~N}_{6}$ sheet, the electronic and magnetic properties are modulated. Fig. 4(a)-(f) show spin-polarised band structure, total density of states (TDOS) and corresponding projected density of state (PDOS) of $\mathrm{Fe} @ \mathrm{C}_{6} \mathrm{~N}_{6}$ unstrained system. The figures portray half metallic electronic character of the Fe@ $\mathrm{C}_{6} \mathrm{~N}_{6}$ system. We can infer that the half-metallic character in $\mathrm{Fe} @ \mathrm{C}_{6} \mathrm{~N}_{6}$ system is a result of electron transfer from Fe sub-orbital induced by ionic interaction between the Fe and the $\mathrm{C}_{6} \mathrm{~N}_{6}$ sheet. The minority band structure in Fig. 4(a) confirms the half-metallic character which shows flat energy spectrum crossing over the Fermi level at conduction band minimum. From the PDOS plots, we can observe a dominant features of Fe atom s-, d- sub-orbitals as well as small contributions by $\mathrm{p}_{z^{-}}$of the surrounding six $\mathrm{N}$ atom in the Fermi level. At approximately $-1.5 \mathrm{eV}$ the bonding orbitals are contributed mainly by sp-like orbitals of the six $\mathrm{N}$ atoms, and the $\mathrm{d}_{x y}, \mathrm{~d}_{x^{2}-y^{2}}$ orbitals of Fe atom in the majority spin state. Around -3.5 $\mathrm{eV}$ there is a mixed hybridization which is dominated by d-orbitals of the Fe atom in the majority spin state and $\mathrm{s}^{-}, \mathrm{p}_{z}$-like orbitals of the surrounding $\mathrm{N}$ atoms in both majority and minority spin state.

When subjected to variations in external environment, i.e. symmetric tensile deformation (up to $6 \%$ bi-axial tensile strain, see Table 2 ) and application of electric field (up to a maximum of $10 \mathrm{~V} / \mathrm{nm}$, see Fig 3(iii)), 
the half-metallic electronic character and magnetic moment of $\mathrm{Fe} @ \mathrm{C}_{6} \mathrm{~N}_{6}$ system are preserved. On the other hand, binding of Fe atom in $\mathrm{Fe}_{0} \mathrm{C}_{6} \mathrm{~N}_{6}$ is enhanced as larger electric field strength is applied. The resulting higher energy of $\mathrm{Fe} @ \mathrm{C}_{6} \mathrm{~N}_{6}$ system which corresponds to an increase $E_{b}$ can be related to repulsive effect between the $\mathrm{p}_{x}, \mathrm{p}_{y}$ orbitals of $\mathrm{N}$ atom and the $\mathrm{d}_{x y}, \mathrm{~d}_{x^{2}-y^{2}}$ orbitals of $\mathrm{Fe}$ atom. This repulsion moves $\mathrm{p}_{z}$ orbital towards higher energy and hence the system energy increases.

\section{Adsorption of atoms and molecules on Fe embedded striazine sheet}

The optimized stable geometries of Fe-embedded s-triazine with adsorbed atoms $(\mathrm{C}, \mathrm{N}, \mathrm{O}, \mathrm{H})$ and molecules $\left(\mathrm{CH}_{4}, \mathrm{~N}_{2}, \mathrm{O}_{2}, \mathrm{H}_{2}, \mathrm{CO}, \mathrm{CO}_{2}\right)$ systems are displayed in Fig. 5 and 6. All atoms in the system are allowed to move freely without any constraint during the structural relaxation. We also listed the geometric parameters of the stable systems in Table 3. For the adsorbed atoms, the parameter $h_{\mathrm{Fe}-X}$ (where $X$ represents atoms/molecules) are within chemisorption bonding height. These calculated bond lengths are indications of interaction between the embedded Fe atom and the adsorbed atoms. Nitrogen atom being the most electronegative has the shortest adsorption height, hence the magnetic moment per unit cell is also the lowest due to the strong interaction. The estimated heights of $h_{\mathrm{Fe}-X}$ are in agreement with the recent work [24]. To determine the stability of the $\mathrm{Fe} @ \mathrm{C}_{6} \mathrm{~N}_{6}$ with adsorbed atoms/molecules systems, we calculate the adsorption energy which is expressed as

$$
E_{\mathrm{ads}}=\left(E_{\mathrm{Fe}-\mathrm{C}_{6} \mathrm{~N}_{6}}+E_{x}\right)-E_{T},
$$

where $E_{T}, E_{\mathrm{Fe}-\mathrm{C}_{6} \mathrm{~N}_{6}}$ and $E_{x}$ denotes the total energy of $\mathrm{Fe}_{0} @ \mathrm{C}_{6} \mathrm{~N}_{6}$ with adsorbates, the energy of $\mathrm{Fe} @ \mathrm{C}_{6} \mathrm{~N}_{6}$ system, and the total energy of an isolated atom or molecules respectively. Positive adsorption energy is an indication of a stable structure. The adsorption energies are listed in Table 3 . The calculated results guarantee the chemical adsorption of all the systems.

As can be seen in Table 3, the adsorption of atoms on $\mathrm{Fe}_{0} \mathrm{C}_{6} \mathrm{~N}_{6}$ sheet modulates the total magnetic moment per unit cell. The total magnetic moment in $\mathrm{Fe} @ \mathrm{C}_{6} \mathrm{~N}_{6}$ with adsorbed $\mathrm{O}$ and $\mathrm{H}$ atoms systems increased whereas we find drastic magnetic moment reduction in $\mathrm{Fe} @ \mathrm{C}_{6} \mathrm{~N}_{6}$ with adsorbed $\mathrm{N}$ and $\mathrm{C}$. The modulation is related to the electron transfer between the Fe 
and the surrounding atoms. As illustrated in Table 3, total magnetic moment is high in cases with large charge transfer from Fe into the surrounding atoms as well as the adsorbed atoms ( $\mathrm{H}$ and $\mathrm{O}$ atoms). This shows that interaction between $\mathrm{Fe}$ and $\mathrm{O}, \mathrm{H}$ relatively preserves the number of unpaired electrons in the $\mathrm{d}$ orbital of Fe. Thus, the atomic magnetic moment of Fe is maintained in those systems. In contrast, Fe@ $\mathrm{C}_{6} \mathrm{~N}_{6}$ with adsorbed $\mathrm{N}$ or $\mathrm{C}$ atoms produce low spin configurations. TDOS of Fe@ $\mathrm{C}_{6} \mathrm{~N}_{6}$ with adsorbed atoms are depicted in Fig. 5. The TDOS figures for Fe@ $\mathrm{C}_{6} \mathrm{~N}_{6}$ with adsorbed $\mathrm{H}$ and $\mathrm{O}$ show semiconductor electronic character whereas $\mathrm{Fe} @ \mathrm{C}_{6} \mathrm{~N}_{6}$ with adsorbed $\mathrm{C}$ and $\mathrm{N}$ maintain half-metallic character. The modulation of halfmetallic character in $\mathrm{Fe} @ \mathrm{C}_{6} \mathrm{~N}_{6}$ into semiconductor when adsorbed by $\mathrm{H}$ and $\mathrm{O}$ is caused by the shift in impurity state towards higher energy.

Next we relaxed the structures of $\mathrm{Fe} @ \mathrm{C}_{6} \mathrm{~N}_{6}$ with six adsorbed molecules $\left(\mathrm{CH}_{4}, \mathrm{~N}_{2}, \mathrm{O}_{2}, \mathrm{H}_{2}, \mathrm{CO}, \mathrm{CO}_{2}\right)$. The stable adsorption height $h_{\mathrm{Fe}-X}$, the corresponding adsorption energies and the bond lengths $d_{\mathrm{avg}-X}$ of an isolated as well as adsorbed molecules are listed in Table 3. It can be seen that the adsorption heights vary slightly for different molecules. The smaller value of $h_{\mathrm{Fe}-X}$ for adsorbed $\mathrm{CO}, \mathrm{O}_{2}$ and $\mathrm{H}_{2}$ is an indication of favourable chemical bonding compared to other adsorbed molecules. Correspondingly, their $d_{\text {avg }-X}$ increases after chemisorption. Interestingly, the adsorption energies for $\mathrm{CO}$ and $\mathrm{O}_{2}$ are almost the same. Our results are in disagreement with the recent report [24]. It was reported that $\mathrm{O}_{2}$ would favourably chemisorbed on the Fe@ $\mathrm{C}_{6} \mathrm{~N}_{6}$ surface as compared to $\mathrm{CO}$ when the two gases are passed into the surface at constant pressure. We used DFT method in our ground state computations, whereas the work in Ref. 24] employed DFT $+U$ in the similar adsorption environment (different graphitic CN allotrope). Despite such a difference in computational methodology, we do not expect a large discrepancy in the computed adsorption energy. As it turns out, our result is in the same order as that of Ref. [24] since the $h_{\mathrm{Fe}-\mathrm{X}}$ for $\mathrm{CO}$ and $\mathrm{O}_{2}$ are almost the same. It indicates strong interaction between $\mathrm{CO}, \mathrm{O}_{2}$ molecules and $\mathrm{Fe}$ atom due to hybridization. The computed adsorption energy for $\mathrm{CO}_{2}$ is within the value suggested by Deng et al. [35].

As illustrated in Table 3, high magnetic moment per unit cell are obtained for different $\mathrm{Fe} @ \mathrm{C}_{6} \mathrm{~N}_{6}$ with adsorbed molecules systems. As can be seen under $M_{\text {atom }}$, the contributions of the magnetic moment in the systems mainly originates from Fe atom. This shows that the high spin configuration of $3 \mathrm{~d}$ electrons of the Fe atom are maintained. Except for $\mathrm{CO}$ and $\mathrm{N}_{2}$ which couple antiferromagnetically with the Fe atoms, the rest of the molecules 
aligned in the same order with the Fe atom. Hence, the increase or decrease in the number of unpaired electrons in the $3 \mathrm{~d}$ orbitals of the Fe atom determines the total magnetic moment. Figs. 6 show the geometries and TDOS of $\mathrm{Fe} @ \mathrm{C}_{6} \mathrm{~N}_{6}$ with adsorbed molecules. It is seen that the half-metallic character of $\mathrm{Fe} @ \mathrm{C}_{6} \mathrm{~N}_{6}$ system can be tuned into a semiconducting one via adsorption of $\mathrm{H}_{2}, \mathrm{O}_{2}$ and $\mathrm{CH}_{4}$ molecules onto its surface.

\section{Conclusion}

In summary, we have investigated the mechanical, geometrical, electronic and magnetic properties of $\mathrm{Fe} @ \mathrm{C}_{6} \mathrm{~N}_{6}$ system under the influence of external environment based on first-principles calculations. Our findings reveal that the binding energy of $\mathrm{Fe} @ \mathrm{C}_{6} \mathrm{~N}_{6}$ can be modulated by an applied tensile strain and perpendicular electric field. The non-magnetic semiconducting property of bare $\mathrm{C}_{6} \mathrm{~N}_{6}$ is modulated upon embedding of Fe atom in the porous site of the sheet. It is found that the $\mathrm{Fe} @ \mathrm{C}_{6} \mathrm{~N}_{6}$ system exhibits half-metallic electronic character with magnetic moment which is in the order of that for an isolated Fe atom. Additionally, the electronic and magnetic properties of the $\mathrm{Fe} @ \mathrm{C}_{6} \mathrm{~N}_{6}$ systems are preserved under a maximum value of $10 \mathrm{~V} / \mathrm{nm}$ in electric field strength and $6 \%$ tensile strain.

Interestingly, we find that the half-metallic electronic character of $\mathrm{Fe} @ \mathrm{C}_{6} \mathrm{~N}_{6}$ system can be tuned into a semiconductor via adsorption of atoms and molecules into the $\mathrm{Fe} @ \mathrm{C}_{6} \mathrm{~N}_{6}$ system. The appearance of semiconducting character is a result of shift in impurity state towards higher energy when the atoms or molecules are adsorbed on Fe@ $\mathrm{C}_{6} \mathrm{~N}_{6}$ surface. The magnetic moment of Fe@ $\mathrm{C}_{6} \mathrm{~N}_{6}$ with adsorbed atoms/molecules is also modified. Our findings may serve as a guide for future applications of $\mathrm{Fe}_{0} \mathrm{C}_{6} \mathrm{~N}_{6}$ structures in spintronics devices.

\section{Acknowledgments}

T. L. Yoon wishes to acknowledge the support of Universiti Sains Malaysia RU grant (No. 1001/PFIZIK/811240). Figures showing atomic model and 2D charge-density difference plots are generated using the XCRYSDEN program Ref. [36]. We gladfully acknowledge Dr. Chan Huah Yong from USM School of Computer Science, and Prof. Mohd. Zubir Mat Jafri from USM School of Physics, for providing us computing resources to carry out part of the calculations done in this paper. 


\section{References}

[1] Y. Z. Abdullahi, T. L. Yoon, M. M. Halim, M. R. Hashim, M. Z. M. Jafri, L. T. Leng, Geometric and electric properties of graphitic carbon nitride sheet with embedded single manganese atom under bi-axial tensile strain, Current Applied Physics 16 (8) (2016) 809-815.

[2] S. Zhang, R. Chi, C. Li, Y. Jia, Structural, electronic and magnetic properties of $3 \mathrm{~d}$ transition metals embedded graphene-like carbon nitride sheet: A DFT + U study, Physics Letters A 380 (14) (2016) 1373-1377.

[3] D. Ghosh, G. Periyasamy, B. Pandey, S. K. Pati, Computational studies on magnetism and the optical properties of transition metal embedded graphitic carbon nitride sheets, Journal of Materials Chemistry C 2 (37) (2014) 7943-7951.

[4] A. AlZahrani, Theoretical investigation of manganese adsorption on graphene and graphane: A first-principles comparative study, Physica B: Condensed Matter 407 (6) (2012) 992-1002.

[5] Y. Z. Abdullahi, M. M. Rahman, S. Abubakar, R. Muhida, H. Setiyanto, Low coverage palladium adsorption on graphene: First principles study, Quantum Matter 4 (2015) 430-435.

[6] F. Ersan, O. Arslanalp, G. Gokoglu, E. Akturk, Effect of adatoms and molecules on the physical properties of platinum-doped and-substituted silicene: A first-principles investigation, Applied Surface Science 371 (2016) 314-321.

[7] M. M. Rahman, Y. Z. Abdullahi, A. Shuaibu, S. Abubakar, H. Zainuddin, R. Muhida, H. Setiyanto, Density functional study of structural stabilities, electric and magnetic properties of vanadium adsorption on graphene, Journal of Computational and Theoretical Nanoscience 12 (2015) 1995-2002.

[8] Z. Zhang, Z. Geng, D. Cai, T. Pan, Y. Chen, L. Dong, T. Zhou, Structure, electronic and magnetic properties of hexagonal boron nitride sheets doped by $5 d$ transition metal atoms: First-principles calculations and molecular orbital analysis, Physica E: Low-dimensional Systems and Nanostructures 65 (2015) 24-29. 
[9] Y. Yagi, T. M. Briere, M. H. Sluiter, V. Kumar, A. A. Farajian, Y. Kawazoe, Stable geometries and magnetic properties of single-walled carbon nanotubes doped with 3 d transition metals: A first-principles study, Physical Review B 69 (7) (2004) 075414.

[10] E. Kroke, M. Schwarz, E. Horath-Bordon, P. Kroll, B. Noll, A. D. Norman, Tri-s-triazine derivatives. Part I. From trichloro-tri-s-triazine to graphitic C3N4 structures, New Journal of Chemistry 26 (5) (2002) 508512 .

[11] M. Asadpour, S. Malakpour, M. Faghihnasiri, B. Taghipour, Mechanical properties of two-dimensional graphyne sheet, analogous system of BN sheet and graphyne-like BN sheet, Solid State Communications 212 (2015) 46-52.

[12] A. Wang, X. Zhang, M. Zhao, Topological insulator states in a honeycomb lattice of s-triazines, Nanoscale 6 (19) (2014) 11157-11162.

[13] Y. Z. Abdullahi, T. L. Yoon, M. M. Halim, M. R. Hashim, T. L. Lim, Mechanical and electronic properties of graphitic carbon nitride sheet: First-principles calculations, Solid State Communications 248 (2016) $144-150$.

[14] Q. H. Wang, K. Kalantar-Zadeh, A. Kis, J. N. Coleman, M. S. Strano, Electronics and optoelectronics of two-dimensional transition metal dichalcogenides, Nature Nanotechnology 7 (11) (2012) 699-712.

[15] X.-H. Li, X. Wang, M. Antonietti, Mesoporous g-C3N4 nanorods as multifunctional supports of ultrafine metal nanoparticles: hydrogen generation from water and reduction of nitrophenol with tandem catalysis in one step, Chem. Sci. 3 (2012) 2170-2174.

[16] J. Zhang, M. Grzelczak, Y. Hou, K. Maeda, K. Domen, X. Fu, M. Antonietti, X. Wang, Photocatalytic oxidation of water by polymeric carbon nitride nanohybrids made of sustainable elements, Chemical Science 3 (2) (2012) 443-446.

[17] X. Zhang, X. Xie, H. Wang, J. Zhang, B. Pan, Y. Xie, Enhanced photoresponsive ultrathin graphitic-phase C3N4 nanosheets for bioimaging, Journal of the American Chemical Society 135 (1) (2012) 18-21. 
[18] X. Zhang, H. Wang, H. Wang, Q. Zhang, J. Xie, Y. Tian, J. Wang, Y. Xie, Single layered graphitic-C3N4 quantum dots for twophoton fluorescence imaging of cellular nucleus, Advanced Materials 26 (26) (2014) 4438-4443.

[19] A. Du, S. Sanvito, S. C. Smith, First-principles prediction of metalfree magnetism and intrinsic half-metallicity in graphitic carbon nitride, Physical Review Letters 108 (19) (2012) 197207.

[20] I. Choudhuri, P. Garg, B. Pathak, Tm@gt-C3N3 monolayers: hightemperature ferromagnetism and high anisotropy, Journal of Materials Chemistry C 4 (35) (2016) 8253-8262.

[21] S. Sun, G. Zhang, N. Gauquelin, N. Chen, J. Zhou, S. Yang, W. Chen, X. Meng, D. Geng, M. N. Banis, R. Li, S. Ye, S. Knights, G. A. Botton, T.-K. Sham, X. Sun, Single-atom catalysis using Pt/graphene achieved through atomic layer deposition, Scientific Reports 3 (2013) 1775 EP -, article.

[22] Y. Ji, H. Dong, H. Lin, L. Zhang, T. Hou, Y. Li, Heptazine-based graphitic carbon nitride as an effective hydrogen purification membrane, RSC Advances 6 (57) (2016) 52377-52383.

[23] Z. Ma, X. Zhao, Q. Tang, Z. Zhou, Computational prediction of experimentally possible g-C3N3 monolayer as hydrogen purification membrane, International Journal of Hydrogen Energy 39 (10) (2014) 50375042 .

[24] D. Ma, Q. Wang, X. Yan, X. Zhang, C. He, D. Zhou, Y. Tang, Z. Lu, Z. Yang, 3d transition metal embedded $\mathrm{C} 2 \mathrm{~N}$ monolayers as promising single-atom catalysts: A first-principles study, Carbon 105 (2016) 463 473.

[25] J. Sirijaraensre, J. Limtrakul, Hydrogenation of $\mathrm{CO}_{2}$ to formic acid over a Cu-embedded graphene: A DFT study, Applied Surface Science 364 (2016) 241-248.

[26] P. Giannozzi, S. Baroni, N. Bonini, M. Calandra, R. Car, C. Cavazzoni, D. Ceresoli, G. L. Chiarotti, M. Cococcioni, I. Dabo, QUANTUM ESPRESSO: a modular and open-source software project for quantum 
simulations of materials, Journal of Physics: Condensed Matter 21 (39) (2009) 395502.

[27] P. Hohenberg, W. Kohn, Inhomogeneous electron gas, Physical Review 136 (3B) (1964) B864.

[28] J. P. Perdew, K. Burke, M. Ernzerhof, Generalized gradient approximation made simple, Physical Review Letters 77 (18) (1996) 3865.

[29] D. Vanderbilt, Soft self-consistent pseudopotentials in a generalized eigenvalue formalism, Physical Review B 41 (11) (1990) 7892.

[30] N. Marzari, D. Vanderbilt, A. De Vita, M. Payne, Thermal contraction and disordering of the Al (110) surface, Physical Review Letters 82 (16) (1999) 3296.

[31] H. J. Monkhorst, J. D. Pack, Special points for Brillouin-zone integrations, Physical Review B 13 (12) (1976) 5188.

[32] E. Cadelano, P. L. Palla, S. Giordano, L. Colombo, Elastic properties of hydrogenated graphene, Physical Review B 82 (23) (2010) 235414.

[33] K. Srinivasu, B. Modak, S. K. Ghosh, Improving the photocatalytic activity of s-triazine based graphitic carbon nitride through metal decoration: an ab initio investigation, Physical Chemistry Chemical Physics 18 (38) (2016) 26466-26474.

[34] P.-O. Lowdin, On the nonorthogonality problem connected with the use of atomic wave functions in the theory of molecules and crystals, The Journal of Chemical Physics 18 (3) (1950) 365-375.

[35] Q. Deng, L. Zhao, X. Gao, M. Zhang, Y. Luo, Y. Zhao, Single layer of polymeric cobalt phthalocyanine: Promising low-cost and high-activity nanocatalysts for CO Oxidation, Small 9 (20) (2013) 3506-3513.

[36] A. Kokalj, Computer graphics and graphical user interfaces as tools in simulations of matter at the atomic scale, Computational Materials Science 28 (2) (2003) 155-168. 
Table 1: Calculated lattice parameters and total strain energy for Fe atom embedded striazine system.

\begin{tabular}{ccccc}
\hline $\begin{array}{c}\text { Strain } \\
(\%)\end{array}$ & $\begin{array}{c}\text { Area } \\
\left(\AA^{2}\right)\end{array}$ & $\begin{array}{c}\text { Total energy } \\
\text { Biaxial } \\
(\mathrm{Ry})\end{array}$ & $\begin{array}{c}\text { Total energy } \\
\text { Uniaxial } \\
(\mathrm{Ry})\end{array}$ & $\begin{array}{c}\text { Lattice } \\
\text { parameter } \\
\text { Biaxial } \\
(\AA)\end{array}$ \\
\hline-0.02 & 167.61 & -998.95042 & -998.98795 & $13.91 / 24.10$ \\
-0.015 & 169.32 & -998.97718 & -998.99904 & $13.98 / 24.22$ \\
-0.01 & 171.05 & -998.99598 & -999.00600 & $14.05 / 24.34$ \\
-0.005 & 172.78 & -999.00762 & -999.00946 & $14.13 / 24.47$ \\
0 & 174.52 & -999.01171 & -999.01171 & $14.20 / 24.59$ \\
0.005 & 176.27 & -999.00880 & -999.01108 & $14.27 / 24.71$ \\
0.01 & 178.03 & -998.99980 & -999.00779 & $14.34 / 24.83$ \\
0.015 & 179.79 & -998.98403 & -999.00136 & $14.41 / 24.96$ \\
0.02 & 181.57 & -998.96248 & -998.99209 & $14.48 / 25.08$ \\
\hline
\end{tabular}


Table 2: The calculated binding energies $E_{b}$, the average bond length between Fe atom and $\mathrm{N}_{\text {edge }}$ atoms $d_{\mathrm{Fe}-N}$, average bond length connecting the s-triazine $d$, and Fe height $h$ (refers to the difference in the $z$-coordinate of the Fe atom and the average of the $z$-coordinate of all the $\mathrm{C}$ and $\mathrm{N}$ atoms in the $\mathrm{C}_{6} \mathrm{~N}_{6}$ sheet). Charge transfer, magnetic moment per unit cell and per Fe atom,electronic character of the $\mathrm{Fe} @ \mathrm{C}_{6} \mathrm{~N}_{6}$ system are denoted by $Q, M_{\text {cell }}, M_{\mathrm{Fe}}$, EC respectively. All the systems are half-metallic.

\begin{tabular}{ccccccccc} 
Strain & $\begin{array}{c}E_{b} \\
(\mathrm{eV})\end{array}$ & $\begin{array}{c}d_{\mathrm{Fe}-\mathrm{N}} \\
(\AA)\end{array}$ & $\begin{array}{c}d \\
(\AA)\end{array}$ & $\begin{array}{c}h \\
(\AA)\end{array}$ & $\begin{array}{c}Q \\
(\text { electrons })\end{array}$ & $\begin{array}{c}M_{\mathrm{Fe}} \\
\left(\mu_{\mathrm{B}}\right)\end{array}$ & $\begin{array}{c}M_{\text {cell }} \\
\left(\mu_{\mathrm{B}}\right)\end{array}$ & $\mathrm{EC}$ \\
\hline $0 \%$ & 4.73 & $2.06-3.40$ & 1.49 & -0.01 & 0.53 & 3.61 & 3.74 & $\mathrm{HM}$ \\
$1 \%$ & 4.56 & $2.06-3.49$ & 1.51 & -0.01 & 0.54 & 3.61 & 3.73 & $\mathrm{HM}$ \\
$2 \%$ & 4.05 & $2.09-3.56$ & 1.53 & 0.00 & 0.56 & 3.61 & 3.71 & $\mathrm{HM}$ \\
$3 \%$ & 3.21 & $2.09-3.64$ & 1.55 & 0.00 & 0.56 & 3.61 & 3.70 & $\mathrm{HM}$ \\
$4 \%$ & 2.06 & $2.02-3.80$ & 1.58 & 0.00 & 0.53 & 3.57 & 3.69 & $\mathrm{HM}$ \\
$5 \%$ & 0.75 & $2.08-3.82$ & 1.61 & 0.00 & 0.54 & 3.57 & 3.66 & $\mathrm{HM}$ \\
$6 \%$ & -0.82 & $2.08-3.91$ & 1.63 & 0.00 & 0.56 & 3.57 & 3.64 & $\mathrm{HM}$ \\
\hline
\end{tabular}


Table 3: $E_{\text {ads }}$ denotes calculated adsorption energy. $h_{\mathrm{Fe}-X}$ denotes averaged height between Fe atom and the adsorbates. $d_{\mathrm{avg}-X}$ denotes bond length of molecules. $X$ represents adsorbate species. The values without parenthesis are that for absorbed molecules while that in parenthesis are for isolated molecules. $Q$ refers to net charge transfer among the adsorbates and the $\mathrm{Fe} @ \mathrm{C}_{6} \mathrm{~N}_{6}$ system. The values without parenthesis are charge transfer from $\mathrm{Fe}$ atom into the sheet or adsorbates. These values are all positive as electron from Fe atom always get transferred into the surrounding. The $Q$ values in parenthesis are charge transfer into the Fe-striazine sheet from adsorbates. Positive values mean electron is transferred into the surroundings $\left(\mathrm{Fe} @ \mathrm{C}_{6} \mathrm{~N}_{6}\right.$ system) from adsorbates, and vice versa. $M_{\text {cell }}$ refers to magnetic moment per unit cell. $M_{\text {atom }}$ refers to magnetic moment of $\mathrm{Fe}$ atom or adsorbates. The values without parenthesis are that for Fe atom, while that in parenthesis are that for the adsorbates. EC refers to the electronic character of the Fe@ $\mathrm{C}_{6} \mathrm{~N}_{6}$ with adsorbates. In the present case, EC can be either half metallic (HM) or semiconducting $(\mathrm{SC})$.

\begin{tabular}{|c|c|c|c|c|c|c|c|}
\hline System & $\begin{array}{l}E_{\text {ads }} \\
(\mathrm{eV})\end{array}$ & $\begin{array}{c}h_{\mathrm{Fe}-X} \\
(\AA)\end{array}$ & $\begin{array}{c}d_{\mathrm{avg}-X} \\
(\AA)\end{array}$ & $\begin{array}{c}Q \\
\text { (electrons) }\end{array}$ & $\begin{array}{l}M_{\text {cell }} \\
\left(\mu_{\mathrm{B}}\right)\end{array}$ & $\begin{array}{c}M_{\text {atom }} \\
\left(\mu_{\mathrm{B}}\right)\end{array}$ & $\mathrm{EC}$ \\
\hline $\mathrm{C}$ & 4.48 & 1.56 & - & $\begin{array}{l}0.13 \\
(0.19)\end{array}$ & 1.68 & $\begin{array}{c}2.17 \\
(-0.71)\end{array}$ & $\mathrm{HM}$ \\
\hline $\mathrm{N}$ & 3.00 & 1.52 & - & $\begin{array}{l}0.24 \\
(0.02)\end{array}$ & 1.56 & $\begin{array}{c}1.53 \\
(-0.12)\end{array}$ & HM \\
\hline $\mathrm{O}$ & 4.11 & 1.65 & - & $\begin{array}{c}0.54 \\
(-0.34)\end{array}$ & 4.57 & $\begin{array}{l}3.45 \\
(0.78)\end{array}$ & $\mathrm{SC}$ \\
\hline $\mathrm{H}$ & 1.90 & 1.60 & - & $\begin{array}{c}0.46 \\
(-0.12)\end{array}$ & 4.31 & $\begin{array}{c}3.93 \\
(0.11)\end{array}$ & $\mathrm{SC}$ \\
\hline $\mathrm{CO}$ & 1.30 & 1.89 & $\begin{array}{c}1.14 \\
(1.16)\end{array}$ & $\begin{array}{c}0.29 \\
\text { (C: } 0.33, \text { O: } 0.09)\end{array}$ & 3.53 & $\begin{array}{c}3.48 \\
(-0.13)\end{array}$ & $\mathrm{SC}$ \\
\hline $\mathrm{CO}_{2}$ & 0.44 & 2.16 & $\begin{array}{l}1.18 \\
(1.18)\end{array}$ & $\begin{array}{c}0.50 \\
\text { (C: } 0.79, \text { O: }-0.41)\end{array}$ & 3.78 & $\begin{array}{l}3.64 \\
(0.24)\end{array}$ & $\mathrm{HM}$ \\
\hline $\mathrm{O}_{2}$ & 1.32 & 1.82 & $\begin{array}{l}1.23 \\
(1.40)\end{array}$ & $\begin{array}{c}0.52 \\
(-0.23)\end{array}$ & 3.70 & $\begin{array}{l}3.12 \\
(0.49)\end{array}$ & $\mathrm{HM}$ \\
\hline $\mathrm{N}_{2}$ & 0.15 & 2.12 & $\begin{array}{l}1.11 \\
(1.14)\end{array}$ & $\begin{array}{l}0.36 \\
(0.2)\end{array}$ & 3.55 & $\begin{array}{c}3.51 \\
(-0.15)\end{array}$ & $\mathrm{HM}$ \\
\hline $\mathrm{H}_{2}$ & 0.31 & 1.87 & $\begin{array}{l}0.75 \\
(0.79)\end{array}$ & $\begin{array}{c}0.42 \\
(0.21)\end{array}$ & 3.68 & $\begin{array}{l}3.53 \\
(0.00)\end{array}$ & $\mathrm{SC}$ \\
\hline $\mathrm{CH}_{4}$ & 0.18 & 2.16 & $\begin{array}{l}1.10 \\
(1.10)\end{array}$ & $\begin{array}{c}0.51 \\
\text { (C: }-0.64, \mathrm{H}: 0.90)\end{array}$ & 3.76 & $\begin{array}{l}3.62 \\
(0.02)\end{array}$ & $\mathrm{SC}$ \\
\hline
\end{tabular}




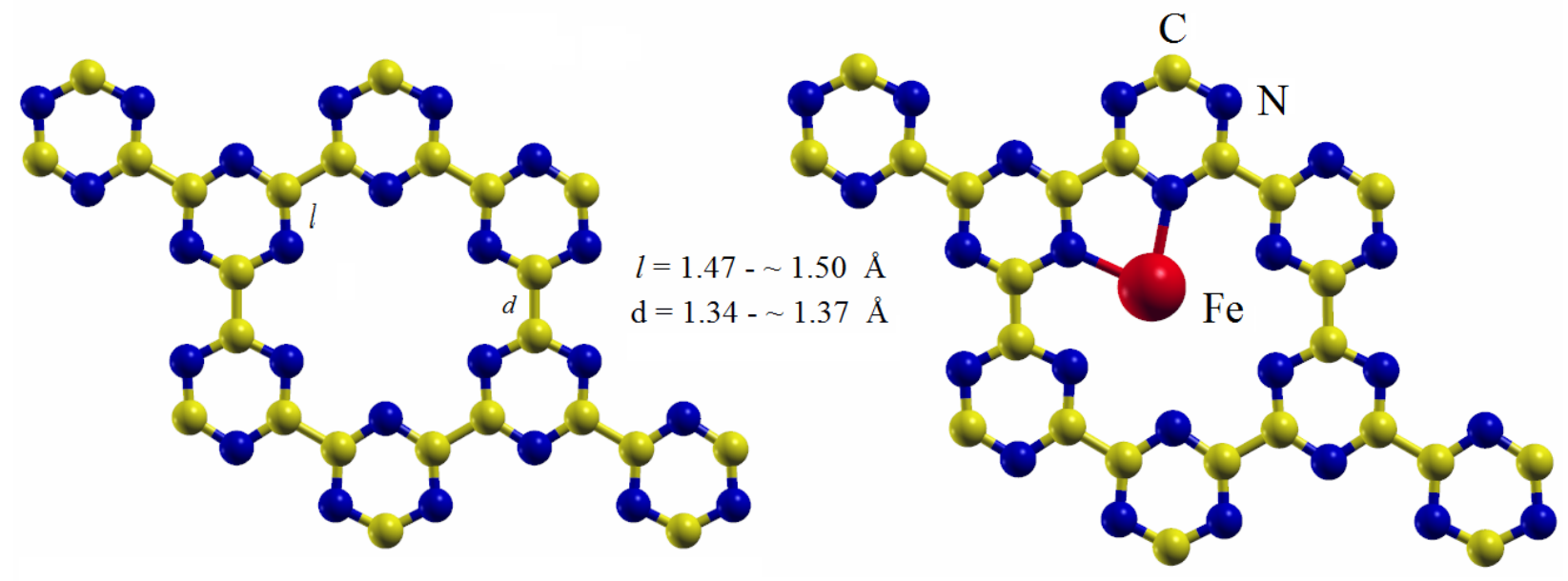

(a)

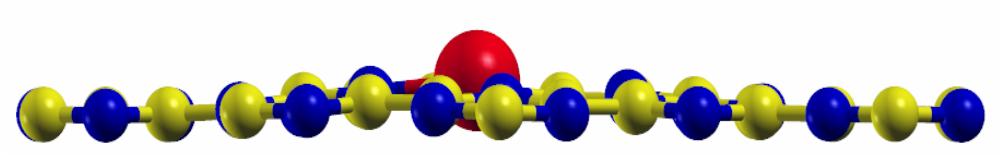

(b)

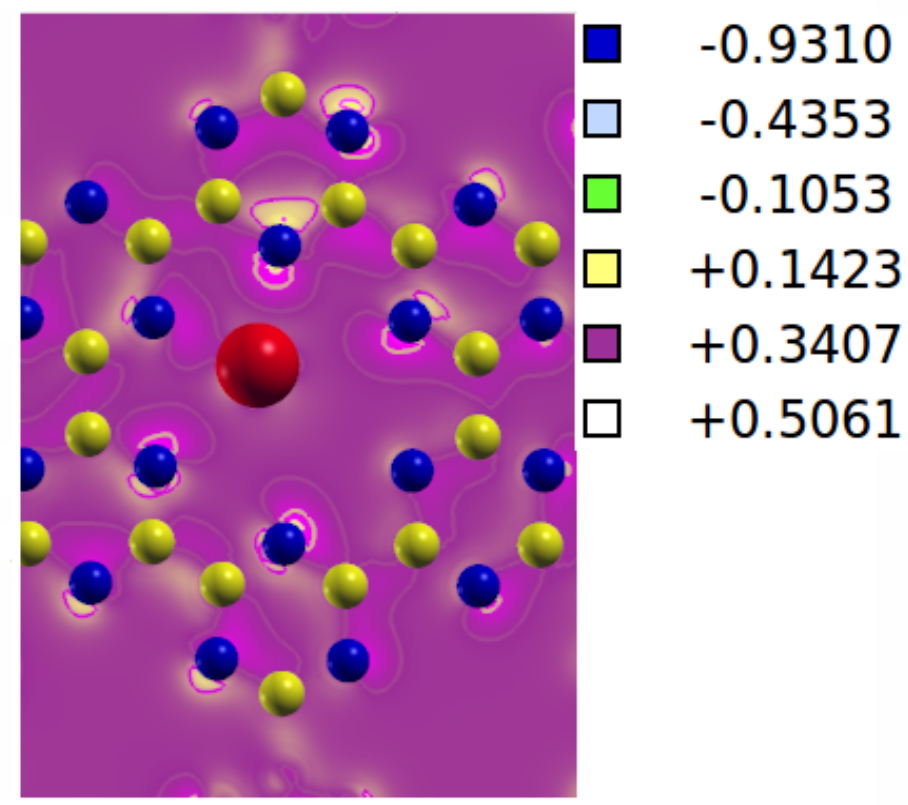

(c)

Figure 1: (a). Relaxed structure of $2 \times 2 \mathrm{C}_{6} \mathrm{~N}_{6}$ sheet (left panel) and relaxed structure (right) of Fe embedded $2 \times 2 \mathrm{C}_{6} \mathrm{~N}_{6}$. (b). Relaxed side view of $2 \times 2 \mathrm{C}_{6} \mathrm{~N}_{6}$ sheet with an embedded Fe atom $\left(\mathrm{Fe} @ \mathrm{C}_{6} \mathrm{~N}_{6}\right)$ under perpendicular electric field strength of $10 \mathrm{~V} / \mathrm{nm}$. (c). Difference charge-density for Fe atom embedded s-triazine. The color scale shows ranges of charge accumulation and depletion in a.u. 

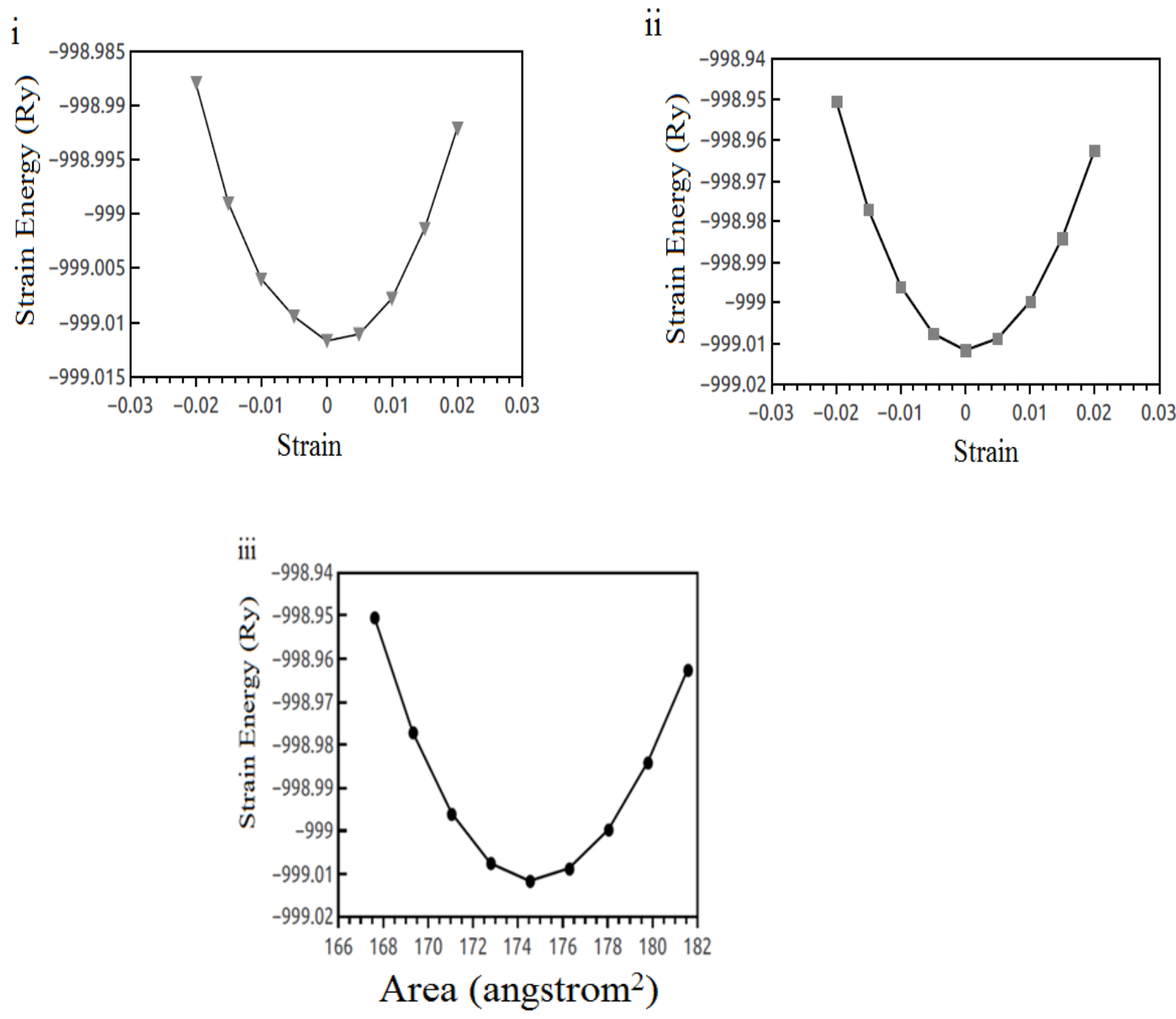

Figure 2: Variation of strain energy (Ry) versus (i) bi-axial tensile strain (ii) uni-axial tensile strain and (iii) area of the $\mathrm{Fe}_{0} \mathrm{C}_{6} \mathrm{~N}_{6}$ system for elastic constant calculation. 

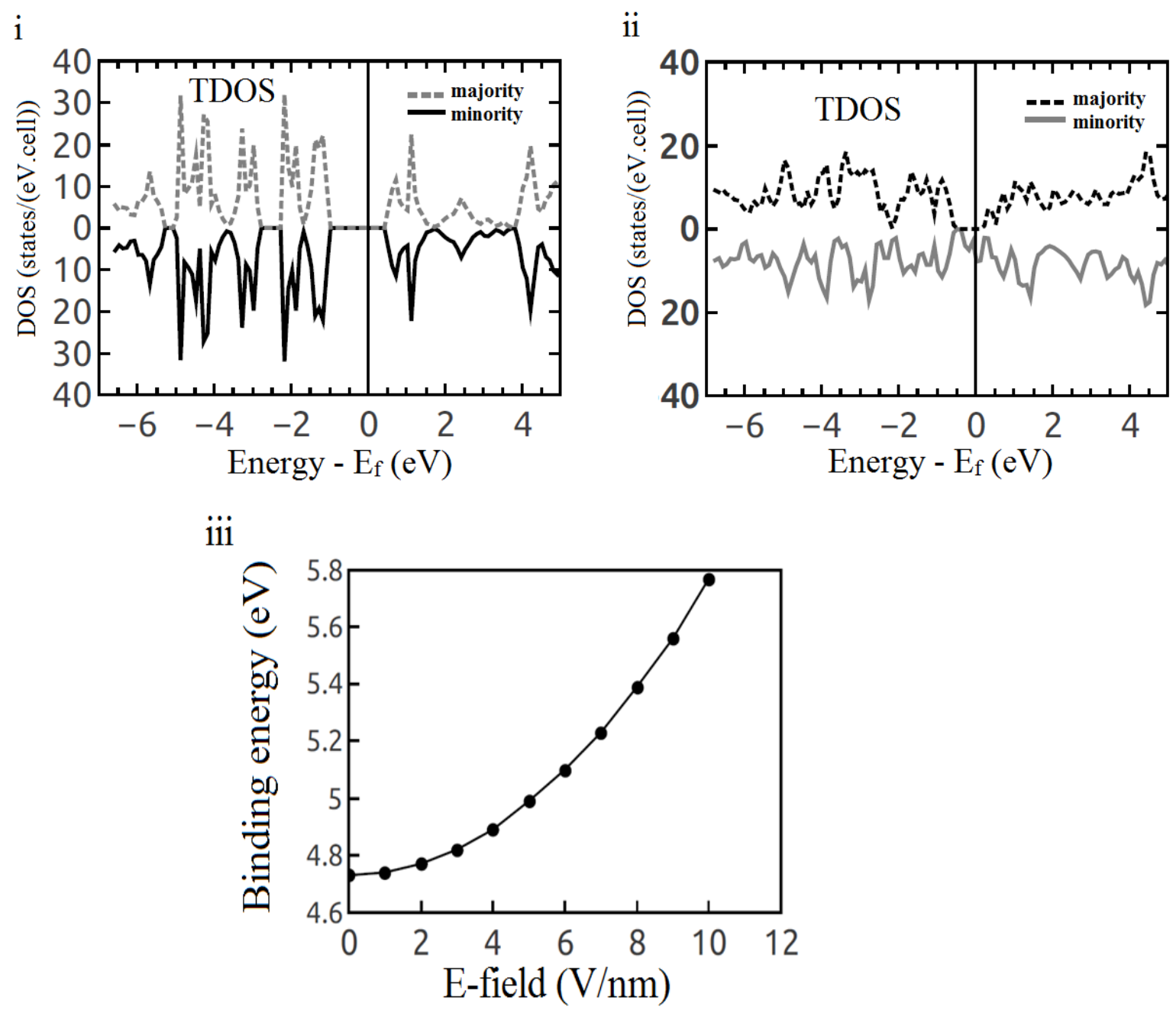

Figure 3: Spin-polarized total density of state (TDOS) for (i) pure s-triazine sheet (ii) $\mathrm{Fe} @ \mathrm{C}_{6} \mathrm{~N}_{6}$ under applied electric field. (ii) Variation of binding energy versus applied electric field strength for Fe@ $\mathrm{C}_{6} \mathrm{~N}_{6}$ system. 
(a)
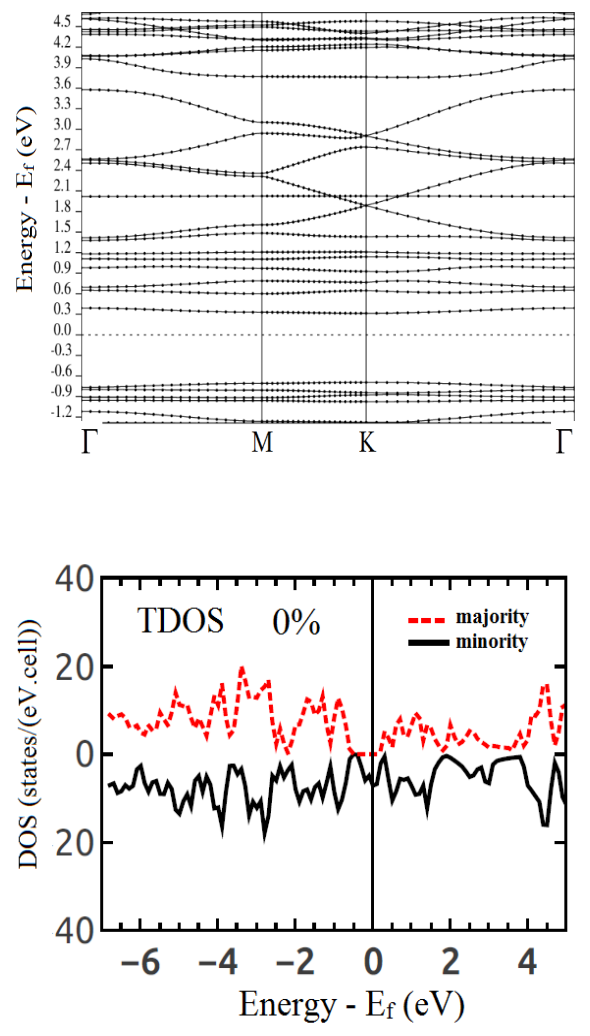

(c)

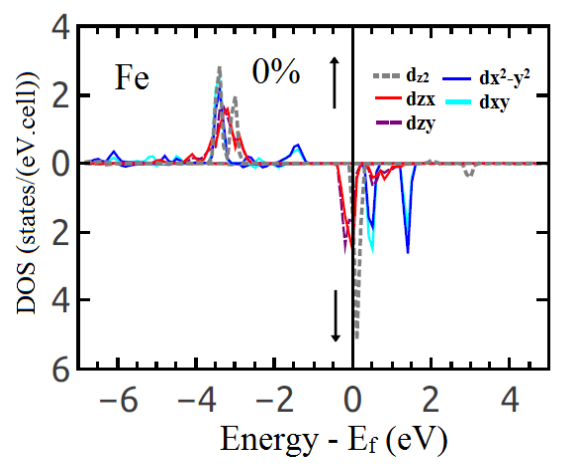

(e)

Figure 4: Spin-polarized electronic band structure (a) majority (b) minority spin states for unstrained $(s=0) \mathrm{Fe}_{0} \mathrm{C}_{6} \mathrm{~N}_{6}$ system. Spin-polarized TDOS and projected density of state (PDOS) for strain-free (c)-(f).
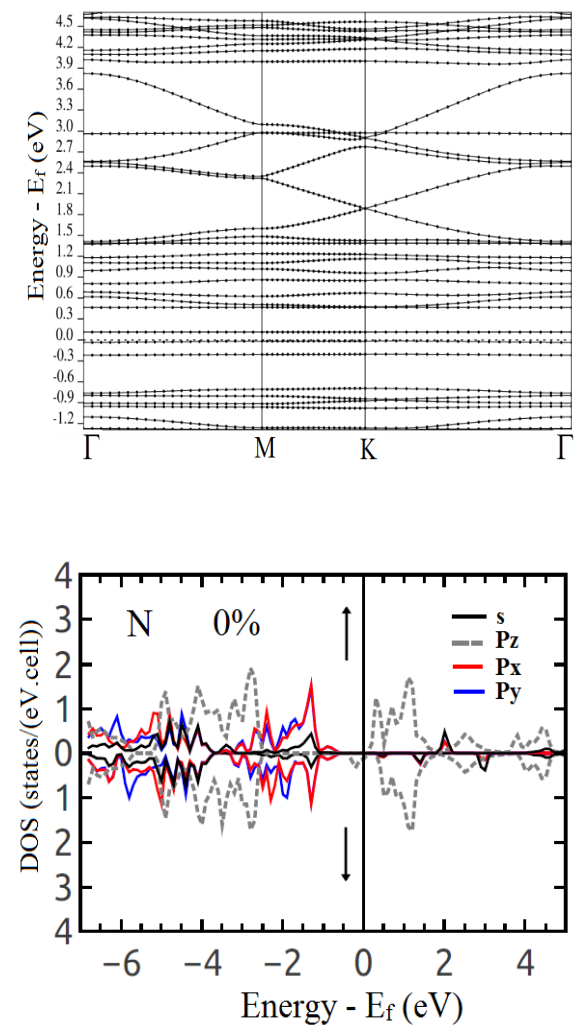

(d)

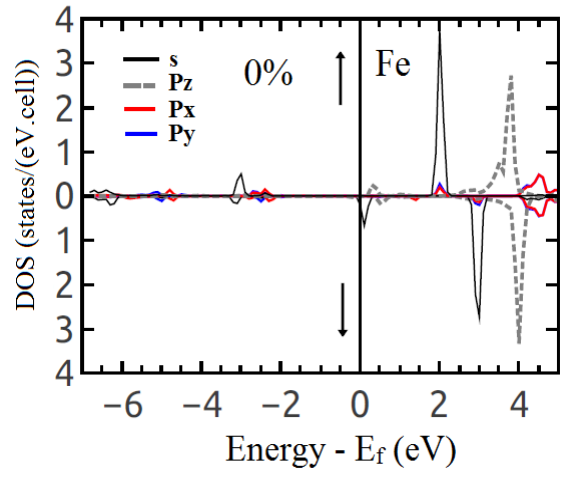



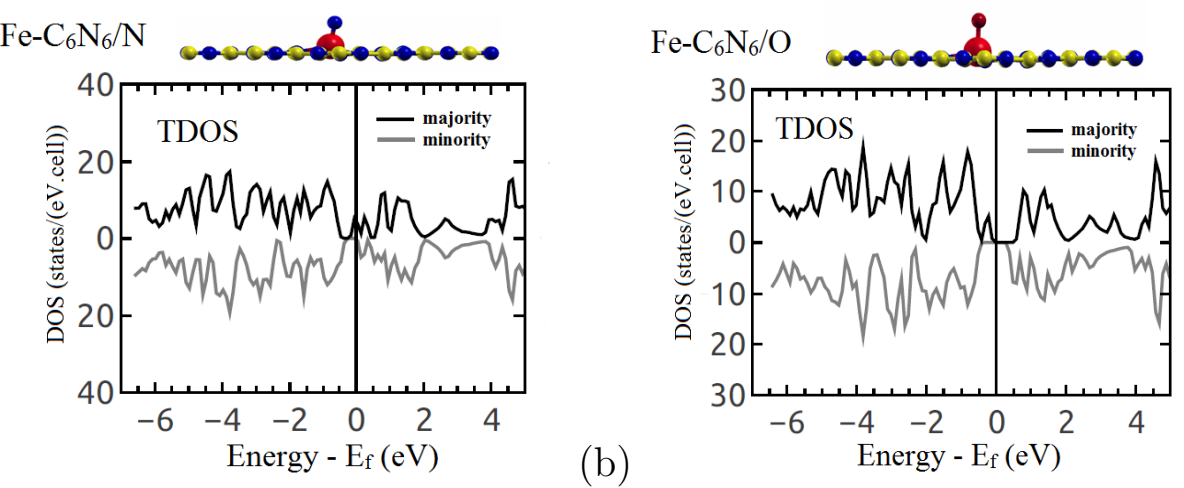

(a)

(b)
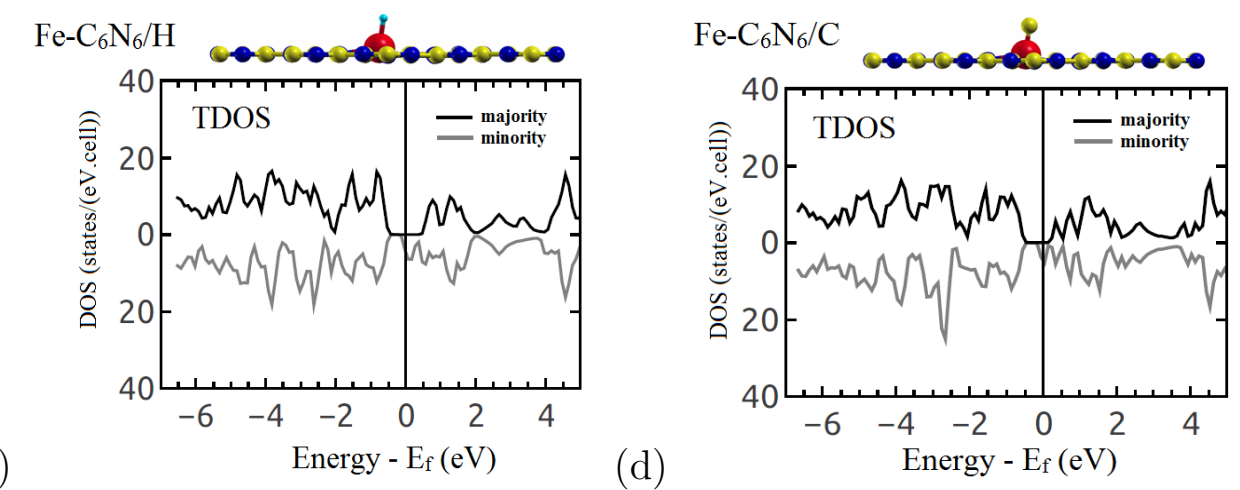

Figure 5: Spin-polarized TDOS and side view for Fe@ $\mathrm{C}_{6} \mathrm{~N}_{6}$ with an adsorbed (a) C (b) N (c) $\mathrm{O}$ and (d) $\mathrm{H}$ atoms systems respectively. 
(a)

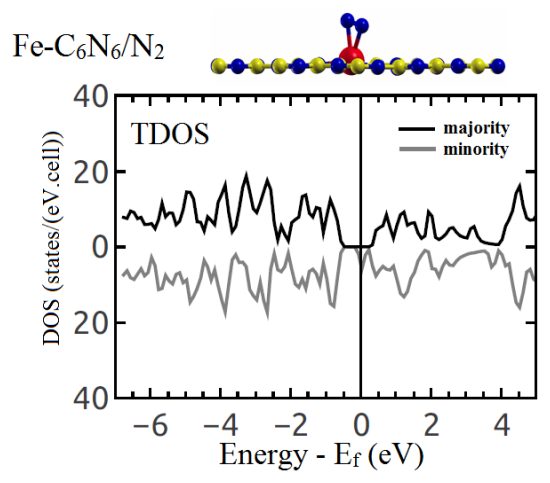

(c)

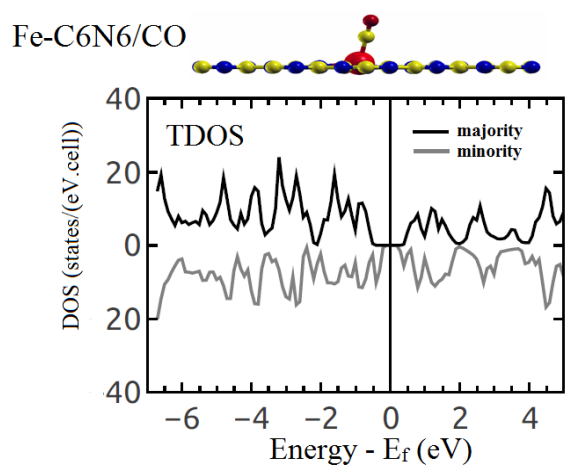

(e)

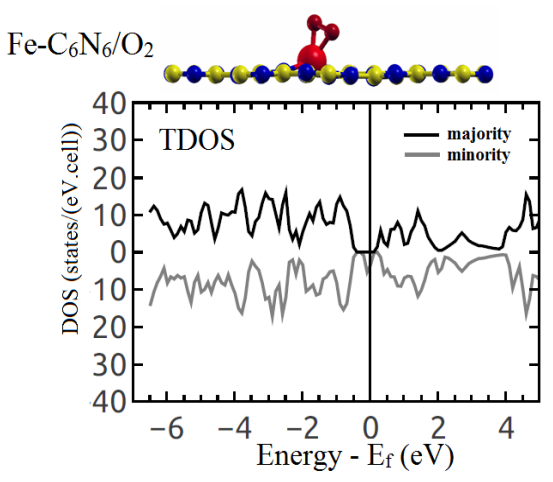

(d)
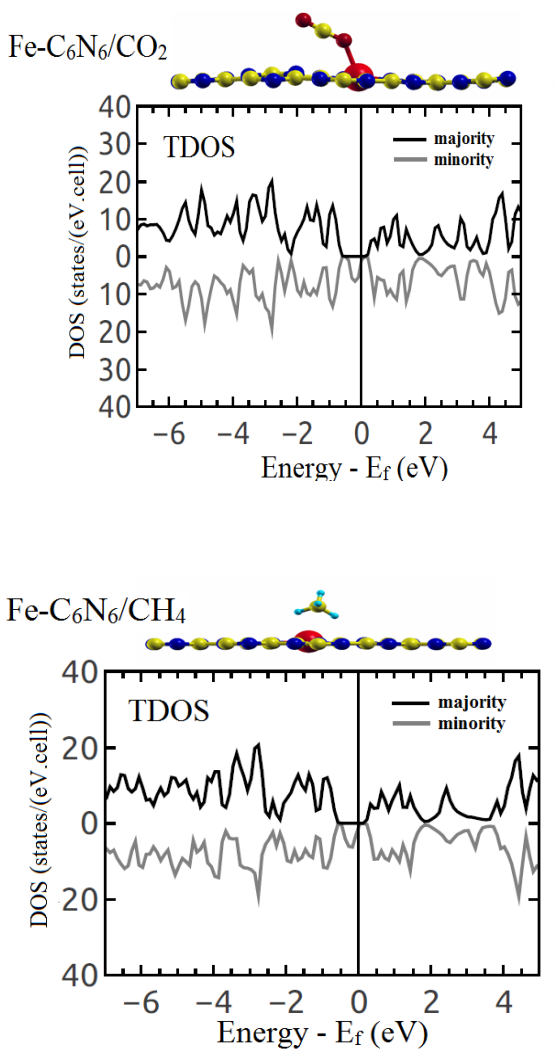

(b)

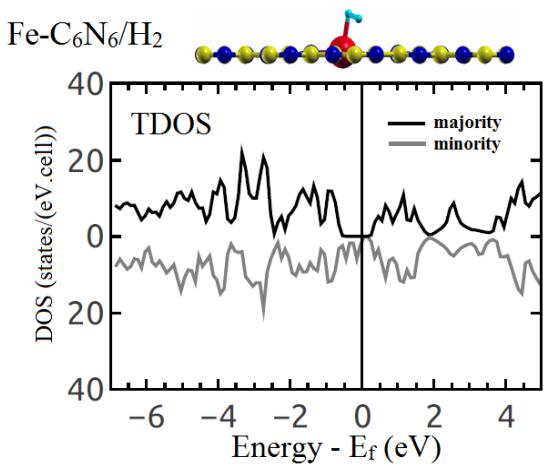

(f)

Figure 6: Spin-polarized TDOS and side view for Fe@ $\mathrm{C}_{6} \mathrm{~N}_{6}$ with an adsorbed (a) $\mathrm{N}_{2}$ (b) $\mathrm{H}_{2}$ (c) $\mathrm{CO}$ (d) $\mathrm{CO}_{2}$ (e) $\mathrm{O}_{2}$ and (f) $\mathrm{CH}_{4}$ molecules systems respectively. 